\title{
Co-existence of virulence factors and antibiotic resistance in new Klebsiella pneumoniae clones emerging in south of Italy
}

Teresa Fasciana ${ }^{1 *}$ (D, Bernardina Gentile ${ }^{2}$, Maria Aquilina ${ }^{1}$, Andrea Ciammaruconi ${ }^{2}$, Chiara Mascarella ${ }^{1}$, Anna Anselmo ${ }^{2}$, Antonella Fortunato ${ }^{2}$, Silvia Fillo², Giancarlo Petralito ${ }^{2}$, Florigio Lista ${ }^{2}$ and Anna Giammanco ${ }^{1}$

\begin{abstract}
Background: Endemic presence of Klebsiella pneumoniae resistant to carbapenem in Italy has been due principally to the clonal expansion of CC258 isolates; however, recent studies suggest an ongoing epidemiological change in this geographical area.

Methods: 50 K. pneumoniae strains, 25 carbapenem-resistant (CR-Kp) and 25 susceptible (CS-Kp), collected from march 2014 to march 2016 at the Laboratory of Bacteriology of the Paolo Giaccone Polyclinic University hospital of Palermo, Italy, were characterized for antibiotic susceptibility and fully sequenced by next generation sequencing (NGS) for the in silico analysis of resistome, virulome, multi-locus sequence typing (MLST) and core single nucleotide polymorphism (SNP) genotypes

Results: MLST in silico analysis of CR-Kp showed that 52\% of isolates belonged to CC258, followed by ST395 (12\%), ST307 (12\%), ST392 (8\%), ST348 (8\%), ST405 (4\%) and ST101 (4\%). In the CS-Kp group, the most represented isolate was ST405 (20\%), followed by ST392 and ST15 (12\%), ST395, ST307 and ST1727 (8\%). The in silico B-lactamase analysis of the CR-Kp group showed that the most detected gene was blaSHV (100\%), followed by blaTEM (92\%), blaKPC (88\%), blaOXA (88\%) and blaCTX-M (32\%). The virulome analysis detected mrk operon in all studied isolates, and wzi-2 was found in three CR-Kp isolates (12\%). Furthermore, the distribution of virulence genes encoding for the yersiniabactin system, its receptor fyuA and the aerobactin system did not show significant distribution differences between CR-Kp and CS-Kp, whereas the Klebsiella ferrous iron uptake system (kfuA, kfuB and kfuC genes), the two-component system kvgAS and the microcin E495 were significantly $(p<0.05)$ prevalent in the CS-Kp group compared to the CR-Kp group.

Core SNP genotyping, correlating with the MLST data, allowed greater strain tracking and discrimination than MLST analysis.
\end{abstract}

Conclusions: Our data support the idea that an epidemiological change is ongoing in the Palermo area (Sicily, Italy). In addition, our analysis revealed the co-existence of antibiotic resistance and virulence factors in CR-Kp isolates; this characteristic should be considered for future genomic surveillance studies.

Keywords: Carbapenem-resistant Klebsiella pneumoniae, Virulence factors

\footnotetext{
* Correspondence: teresa.fasciana@virgilio.it

${ }^{1}$ Department of Health Promotion, Mother and Child Care, Internal Medicine

and Medical Specialties, University of Palermo, Via del Vespro 133, 90127

Palermo, Italy

Full list of author information is available at the end of the article
}

(c) The Author(s). 2019 Open Access This article is distributed under the terms of the Creative Commons Attribution 4.0 International License (http://creativecommons.org/licenses/by/4.0/), which permits unrestricted use, distribution, and reproduction in any medium, provided you give appropriate credit to the original author(s) and the source, provide a link to the Creative Commons license, and indicate if changes were made. The Creative Commons Public Domain Dedication waiver (http://creativecommons.org/publicdomain/zero/1.0/) applies to the data made available in this article, unless otherwise stated. 


\section{Background}

The World Health Organization (WHO), the US Centers for Disease Control and Prevention (CDC) and the UK Department of Health have indicated Klebsiella pneumoniae as one of the multi drug resistant (MDR) microorganisms constituting an immediate threat for human health [1-3]. K. pneumoniae, an opportunistic pathogen, has emerged not only thanks to its ability to accumulate multiclass antibiotic resistance determinants over time [1] but also, as widely reported, to its adeptness in causing severe community- and hospital-associated infections [4-6].

K. pneumoniae "permeability" to mobile genetic elements is a key factor for its dissemination not only with respect to the possibility of becoming resistant to antibiotics, but also of evolving towards more virulent phenotypes thanks to genes that may provide a survival benefit to microorganisms $[7,8]$. However, in $K$. pneumoniae the relation between resistance and virulence is a complex issue since a systematic understanding of its population structure is still lacking $[4,9]$. This makes it difficult to perceive the emergence of new clones, what instead could be an advantageous approach to develop epidemiological surveillance programs and avoid outbreaks, particularly of strains which have become resistant to carbapenem (carbapenem-resistant K. pneumoniae, CR-Kp) [9-11].

The existing body of research on carbapenemresistance mechanisms suggests that the production of K. pneumoniae carbapenemase (KPC) encoded by the plasmidic gene blaKPC is the most common one and its rapid dissemination has typically been caused by the clonal expansion of clonal complex (CC) 258 strains, including ST258 and ST512 [12-16]. In Italy, the first KPC-positive $K$. pneumoniae, belonging to ST258, was isolated in Florence in 2008 [17]. Since then, the diffusion of these strains has been evident. In fact, the last European Antimicrobial Resistance Surveillance Network report has confirmed an average prevalence of CR-Kp of up to $33.9 \%$, percentages that make Italy an endemic country for this microorganism $[18,19]$.

To date, although some research has been carried out on the diffusion and genetic characteristics of KPCpositive K. pneumoniae in our region (Sicily, Italy), no single study exists which has comprehensively described these strains considering all of the Hospital's Departments for a period longer than 1 year [20-24].

In this study, we fully sequenced $50 \mathrm{~K}$. pneumoniae strains, both carbapenem resistant and -susceptible, collected from March 2014 to March 2016 at the Laboratory of Bacteriology of the Department of Sciences for Health Promotion and Mother-Child Care "G. D'Alessandro" (Paolo Giaccone Polyclinic University Hospital, University of Palermo, Italy).
The primary aim of this study was to take a current snapshot of the distribution of $K$. pneumoniae in our geographic area by: 1) characterizing the virulome and resistome of CR-Kp clones; 2) assessing the extent to which virulence determinants were carried by CR-Kp and CS-Kp (carbapenem susceptible K. pneumoniae); 3) investigating the phylogenetic correlations among samples by Multilocus sequence typing (MLST) in silico and the analysis of core single nucleotide polymorphisms (SNPs).

\section{Methods}

Bacterial strains and antimicrobial susceptibility testing Species and antimicrobial susceptibility were determined using the Becton- Dickinson Phoenix ${ }^{\mathrm{Tm}}$ automated system (Becton Dickinson, Sparks, MD, USA). Resistance to carbapenem was established by interpreting the results of the antimicrobial susceptibility test on the basis of the breakpoint criteria of the European Committee on Antimicrobial Susceptibility Testing [25]. On the base of carbapenem susceptibility the 50 strains were divided in 25 isolates resistant (CR-Kp) and 25 sensitive (CS-Kp). Table 1 shows the entire clinical sample and the departments of isolation.

\section{DNA isolation}

The template DNA was prepared from bacterial colonies grown for $18 \mathrm{~h}$ on Blood Agar plates. Colonies were picked and suspended in $500 \mu \mathrm{l}$ of ultra-pure DNase-free water. The suspension was harvested at $14000 \mathrm{rpm}$ for $10 \mathrm{~min}$. The supernatants were discarded while DNA from the pellets were extracted using the QIAmp ${ }^{\oplus}$ DNA Mini kit Qiagen (QIAGEN; Hilden, Germany), the quantity and purity of the DNA were determined using NanoDrop 8000 spectrophotometer (Thermo Fisher Scientific, Waltham).

\section{Whole-genome sequencing}

Isolate's genomes were fully sequenced at the Scientific Department, Army Medical Center, Military Polyclinic of Rome (Italy) using the next-generation sequencing on the Illumina MiSeq platform (San Diego, CA, USA) as recommended by the manufacturer. The library sizes had peaks centered from 900 to $1000 \mathrm{bp}$.

The reads were de novo assembled into contigs using AByss, version 1.5.2 (k parameter $=63$ ) [22]. Contigs longer than $500 \mathrm{bp}$ were selected using an ad hoc script and kept for further analysis. The final assembly ranged from 44 to 414 (median: 143) contigs per sample (N50: 335, 064-64,441; median: 111,289). Contigs were merged through the Minimus2 software (Sommer et al., 2007) and resulting DNA sequences were analysed for similarity using the database sequences by the Standard $\mathrm{Nu}$ cleotide BLAST program (http://blast.ncbi.nlm.nih.gov/ 
Table $1 \mathrm{~K}$. pneumoniae CR and CS isolates, department of isolations, host disease, host age and clinical sample

\begin{tabular}{|c|c|c|c|c|c|c|c|c|c|}
\hline $\begin{array}{l}\text { CR- } \\
\mathrm{Kp} \\
\mathrm{ID}\end{array}$ & Department & host disease & $\begin{array}{l}\text { host } \\
\text { age }\end{array}$ & Sample & $\begin{array}{l}\text { CS- } \\
\mathrm{Kp} \\
\mathrm{ID}\end{array}$ & Department & host disease & $\begin{array}{l}\text { host } \\
\text { age }\end{array}$ & Sample \\
\hline $1 \mathrm{R}$ & $\begin{array}{l}\text { General surgeries } \\
\text { emergencies }\end{array}$ & sepsi & 70 & Blood PVC & $1 \mathrm{~S}$ & $\begin{array}{l}\text { Endocrinology and } \\
\text { Metabolic diseases }\end{array}$ & $\mathrm{ICU}$ & 75 & Urine \\
\hline $2 R$ & $\begin{array}{l}\text { Anaesthesia and } \\
\text { resuscitation }\end{array}$ & sepsi & 46 & Blood CVC & $2 S$ & Surgical Oncology & $\mathrm{ICU}$ & 81 & Urine \\
\hline $3 R$ & $\begin{array}{l}\text { Anaesthesia and } \\
\text { resuscitation }\end{array}$ & sepsi & 59 & Blood PVC & $3 S$ & $\begin{array}{l}\text { Nephrology and } \\
\text { Hypertension }\end{array}$ & $\mathrm{ICU}$ & 70 & Urine \\
\hline $4 R$ & $\begin{array}{l}\text { Anaesthesia and } \\
\text { resuscitation }\end{array}$ & pneumoniae & 60 & $\begin{array}{l}\text { Bronchoalveolar } \\
\text { lavage }\end{array}$ & $4 S$ & Clinical Respiratory Medicine & $\mathrm{ICU}$ & 64 & Urine \\
\hline $5 R$ & $\begin{array}{l}\text { General surgeries } \\
\text { emergencies }\end{array}$ & sepsi & 36 & $\begin{array}{l}\text { Intra-abdominal } \\
\text { fluid }\end{array}$ & $5 S$ & $\begin{array}{l}\text { General and Thoracic } \\
\text { Surgery }\end{array}$ & $\mathrm{ICU}$ & 52 & Wound swab \\
\hline $6 \mathrm{R}$ & $\begin{array}{l}\text { Internal Medicine } \\
\text { Cardioangiology }\end{array}$ & sepsi & 36 & Blood PVC & $6 S$ & Geriatric medicine & $\begin{array}{l}\text { infected } \\
\text { wound }\end{array}$ & 21 & Urine \\
\hline $7 \mathrm{R}$ & Cardiac surgery & sepsi & 53 & Blood CVC & $7 S$ & Geriatric medicine & $\mathrm{ICU}$ & 82 & Ulcer swab \\
\hline $8 R$ & $\begin{array}{l}\text { Clinical Respiratory } \\
\text { Medicine }\end{array}$ & $\mathrm{ICU}$ & 77 & Urine & $8 S$ & Plastic surgery & $\begin{array}{l}\text { infected } \\
\text { wound }\end{array}$ & 82 & Tissue \\
\hline $9 R$ & Internal Medicine & $\mathrm{ICU}$ & 49 & Urine & $9 S$ & Clinical Respiratory Medicine & $\begin{array}{l}\text { infected } \\
\text { wound }\end{array}$ & 74 & Urine \\
\hline $10 \mathrm{R}$ & $\begin{array}{l}\text { Clinical Respiratory } \\
\text { Medicine }\end{array}$ & ICU & 79 & Urine & $10 \mathrm{~S}$ & $\begin{array}{l}\text { Internal Medicine } \\
\text { Cardioangiology }\end{array}$ & $\mathrm{ICU}$ & 76 & Sputum \\
\hline $11 \mathrm{R}$ & Geriatric medicine & $\mathrm{ICU}$ & 90 & Urine & $11 \mathrm{~s}$ & Infectious disease & pneumoniae & 77 & Sputum \\
\hline $12 \mathrm{R}$ & $\begin{array}{l}\text { Endocrinology and } \\
\text { Metabolic diseases }\end{array}$ & ICU & 84 & Urine & $12 \mathrm{~S}$ & Clinical Respiratory Medicine & pneumoniae & 22 & $\begin{array}{l}\text { Bronchoalveolar } \\
\text { lavage }\end{array}$ \\
\hline $13 \mathrm{R}$ & $\begin{array}{l}\text { Anaesthesia and } \\
\text { resuscitation }\end{array}$ & sepsi & 70 & Blood PVC & $13 S$ & $\mathrm{NICU}$ & pneumoniae & 81 & $\begin{array}{l}\text { Endotracheal } \\
\text { tube }\end{array}$ \\
\hline $14 \mathrm{R}$ & $\begin{array}{l}\text { Internal Medicine } \\
\text { Cardioangiology }\end{array}$ & sepsi & 54 & CVC & $14 S$ & $\begin{array}{l}\text { Haematology and Bone } \\
\text { Marrow Transplantation }\end{array}$ & pneumoniae & $\begin{array}{l}15 \\
\text { days }\end{array}$ & Sputum \\
\hline $15 \mathrm{R}$ & Cardiac surgery & pneumoniae & 72 & $\begin{array}{l}\text { Bronchoalveolar } \\
\text { lavage }\end{array}$ & $15 S$ & Rheumatology & pneumoniae & 83 & Urine \\
\hline $16 \mathrm{R}$ & $\begin{array}{l}\text { Anaesthesia and } \\
\text { resuscitation }\end{array}$ & $\mathrm{ICU}$ & 60 & Urine & $16 S$ & Internal Medicine & $\mathrm{ICU}$ & 73 & Sputum \\
\hline $17 \mathrm{R}$ & $\begin{array}{l}\text { Internal Medicine } \\
\text { Cardioangiology }\end{array}$ & $\begin{array}{l}\text { infected } \\
\text { wound }\end{array}$ & 38 & Ulcer swab & $17 \mathrm{~S}$ & Geriatric medicine & pneumoniae & 76 & Urine \\
\hline $18 \mathrm{R}$ & $\begin{array}{l}\text { Internal Medicine } \\
\text { Cardioangiology }\end{array}$ & pneumoniae & 77 & Sputum & $18 \mathrm{~S}$ & Rheumatology & $\mathrm{ICU}$ & 36 & Urine \\
\hline $19 R$ & Cardiac surgery & $\begin{array}{l}\text { infected } \\
\text { wound }\end{array}$ & 71 & Wound swab & $19 S$ & Clinical Respiratory Medicine & $\mathrm{ICU}$ & 91 & Sputum \\
\hline $20 \mathrm{R}$ & $\begin{array}{l}\text { Clinical Respiratory } \\
\text { Medicine }\end{array}$ & ICU & 80 & Urine & $20 S$ & $\begin{array}{l}\text { General surgeries } \\
\text { emergencies }\end{array}$ & pneumoniae & 63 & Liquor \\
\hline $21 \mathrm{R}$ & $\begin{array}{l}\text { General surgeries } \\
\text { emergencies }\end{array}$ & $\begin{array}{l}\text { bile } \\
\text { infections }\end{array}$ & 65 & Bile & $21 \mathrm{~S}$ & $\begin{array}{l}\text { Internal Medicine } \\
\text { Cardioangiology }\end{array}$ & Meningitidis & 92 & Urine \\
\hline $22 \mathrm{R}$ & $\begin{array}{l}\text { Anaesthesia and } \\
\text { resuscitation }\end{array}$ & sepsi & 70 & Blood CVC & $22 \mathrm{~S}$ & Anaesthesia and resuscitation & $\mathrm{ICU}$ & 82 & Urine \\
\hline $23 \mathrm{R}$ & Cardiac surgery & pneumoniae & 62 & Sputum & $23 S$ & $\begin{array}{l}\text { Haematology and Bone } \\
\text { Marrow Transplantation }\end{array}$ & $\mathrm{ICU}$ & 70 & Cutaneous swab \\
\hline $24 \mathrm{R}$ & $\begin{array}{l}\text { General surgeries } \\
\text { emergencies }\end{array}$ & sepsi & 72 & $\begin{array}{l}\text { Intra-abdominal } \\
\text { fluid }\end{array}$ & $24 S$ & Tourism and Migration & $\begin{array}{l}\text { infected } \\
\text { wound }\end{array}$ & 81 & Urine \\
\hline $25 \mathrm{R}$ & $\begin{array}{l}\text { General surgeries } \\
\text { emergencies }\end{array}$ & sepsi & 54 & Abscess fluid & $25 S$ & $\begin{array}{l}\text { Internal Medicine } \\
\text { Cardioangiology }\end{array}$ & $\mathrm{ICU}$ & 71 & Urine \\
\hline
\end{tabular}

CVC: central venous catheter, ICU: intensive care unit, NICU: neonatal intensive care unit, PVC: Peripheral venous catheter 
Blast.cgi). Illumina-generated sequence data for the whole data set of this study have been deposited at NCBI (BioProject id: PRJNA515715 and accession number SUB5047324).

\section{Analysis of virulome and resistome}

Virulome of all $K$. pneumoniae sample was analysed using the VirulenceFinder-1.4 tool and the Pasteur K. pneumoniae database. The resistome of carbapenem-resistant $K$. pneumoniae was analysed using the ResFinder-2.1 software (default identity thresholds [ID] 98\%) which was provided by the Center for Genomic Epidemiology (http:// www.genomicepidemiology.org) and the resources of the Pasteur MLST K. pneumoniae database.

\section{Multilocus sequence typing (MLST) in silico}

he in silico MLST analysis was made by comparing the whole-genome sequences against the $K$. pneumoniae alleles profiles available at http://www.pasteur. $\mathrm{fr} / \mathrm{mlst}$ (Genotyping of Pathogens and Public Health, Institute Pasteur, Paris, France).

\section{Core single-nucleotide polymorphisms (SNPs)}

Phylogenetic analysis based on genome-wide single nucleotide polymorphisms (SNPs) were conducted detecting SNPs through the kSNP v2.1.2 program $(k$-mer $=21)$, which defines a SNP locus as an oligo of length $k$ surrounding a central SNP allele [26]. Maximum likelihood tree based on the 57,766 core SNPs identified by kSNP program was visualised using the Dendroscope v3.2.10 software [27]. Strain 8S, K. pseudopneumoniae, was used as outgroup to root the tree.

\section{Statistical analysis}

Data were expressed as absolute numbers or percentages. The Chi-squared test was used to compare proportions (as appropriate). Values of $p<0.05$ were considered statistically significant. The statistical analysis were performed with MedCalc Statistical software version 16.8 (MedCalc Software bvba, Ostend, Belgium; https://www.medcalc.org; 2016).

\section{Results}

CR-Kp were mainly isolated from blood and urinary samples (28\% for both) (Fig. 1), while the ward from which CR-Kp was primarily isolated was the Anaesthesia and Resuscitation Department (24\%) (Table 1). Regarding CS-Kp, urines were the major isolation sample (52\%) (Fig. 1), while the ward from which CS-Kp was primarily isolated was the Respiratory Department (52\%) (Table 1).

\section{Antibiotic resistance}

The percentages of antibiotic resistance among $K$. pneumoniae carbapenem-resistant and carbapenem-susceptible strains are reported in Table 2. As shown, the CR-Kp group displayed a higher percentage of resistance for all tested antibiotics compared to the susceptible group. Statistical significance was calculated where applicable. In particular, $20 \%$ of CR-Kp and $4 \%$ of CS-Kp were colistin-resistant. Complete antibiotic resistance profile of CR-Kp are shown in Additional file 1.

MLST analysis and Core single-nucleotide polymorphisms (SNPs) phylogenetic analysis

MLST in silico analysis of CR-Kp revealed that $52 \%$ belonged to CC258. In particular, 5 strains were ST258 (20\%) and 8 were ST512 (32\%). The remaining 12 strains

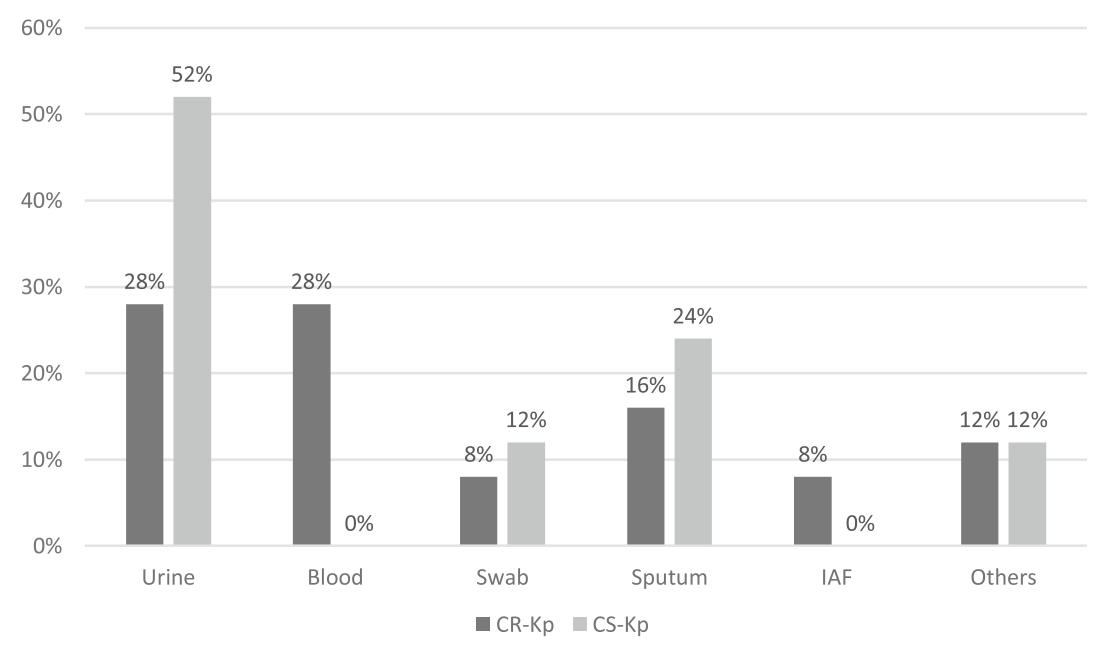

Distribution of CR-Kp and CS-Kp in different samples

Fig. 1 Samples from where isolated the strains 
Table 2 Percentage of antibiotic resistance in carbapenem resistant and susceptible K. pneumoniae

\begin{tabular}{|c|c|c|c|c|}
\hline Class & Antibiotics & K. pneumoniae CR \% & K. pneumoniae CS \% & $P$ value \\
\hline Aminoglicosydes & Gentamycin & 64 & 48 & 0.022 \\
\hline \multirow[t]{3}{*}{ Carbapenems } & Imipenem & 100 & 0 & NA \\
\hline & Meropenem & 100 & 0 & NA \\
\hline & Ertapenem & 100 & 0 & NA \\
\hline Monobactams & Aztreonam & 100 & 60 & NA \\
\hline Fluoroquinolones & Ciprofloxacin & 100 & 64 & NA \\
\hline $\begin{array}{l}\text { Sulfonamides- } \\
\text { Trimethoprim }\end{array}$ & Trimethoprim-sulfamethoxazole & 76 & 60 & 0.015 \\
\hline \multirow[t]{2}{*}{ Penicillin } & Amoxicillin/ clavulanic acid & 100 & 56 & NA \\
\hline & Piperacillin/tazobactam & 100 & 44 & NA \\
\hline \multirow[t]{5}{*}{ Cephalosporin } & Cefotaxime & 100 & 60 & NA \\
\hline & Cefuroxime & 100 & 60 & NA \\
\hline & Cefepime & 88 & 56 & 0 \\
\hline & Ceftazidime & 100 & 60 & NA \\
\hline & Fosfomycin c/G6P & 36 & 16 & 0.001 \\
\hline Tetracyclin & Tigecyclin & 8 & 4 & 0.233 \\
\hline Colistin & & 20 & 4 & 0 \\
\hline
\end{tabular}

NA: chi-squared test not applicable

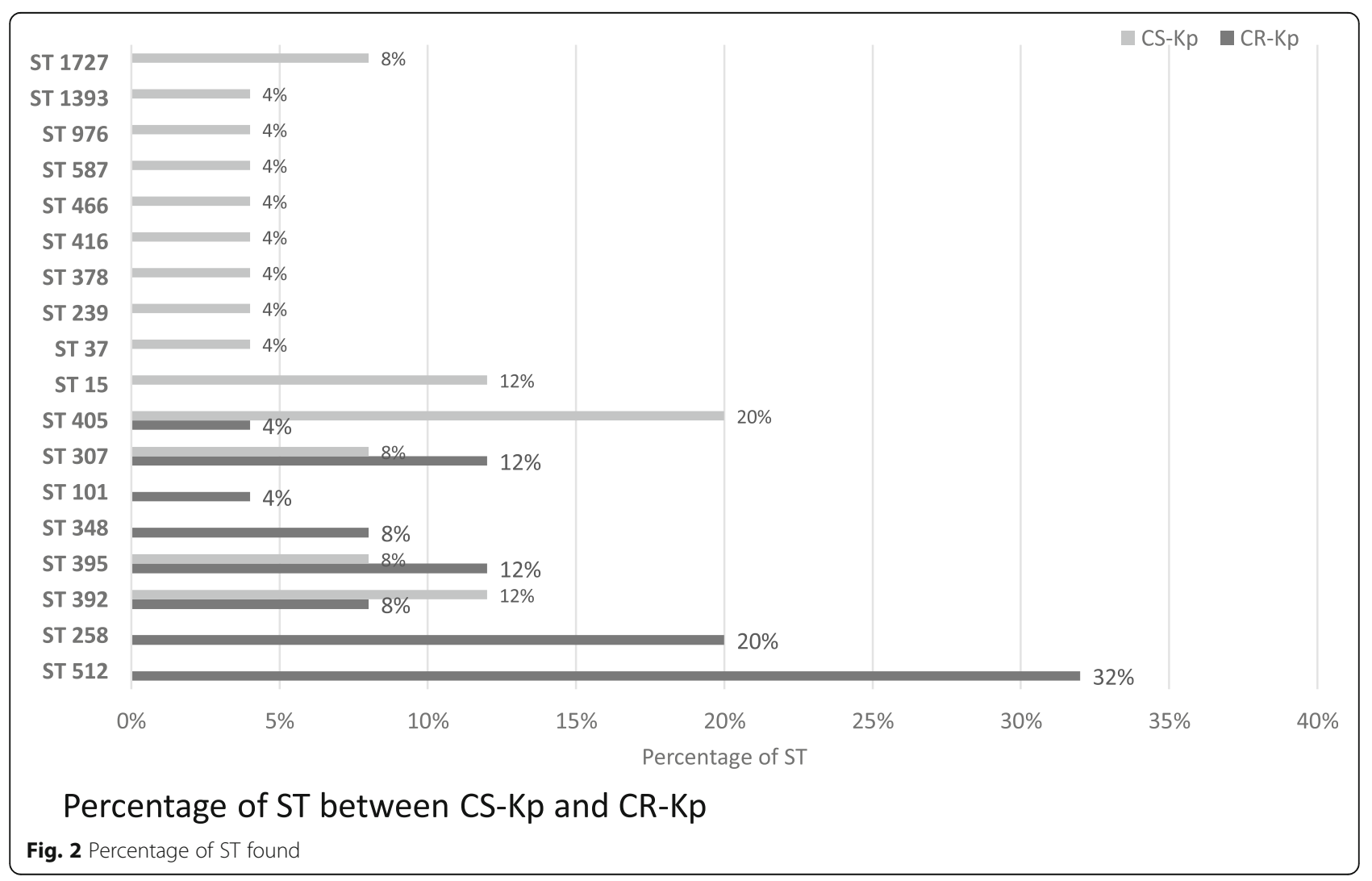


were distributed as follows: 3 were ST395 (12\%), 3 were ST307 (12\%), 2 were ST392 (8\%), 2 were ST348 (8\%), 1 was ST405 (4\%) and 1 was ST101 (4\%). Among CS-Kp's we detected 14 different STs. ST405 was the most represented (5 strains, 20\%), followed by ST392 and ST15 (3 strains, 12\%), ST395, ST307 and ST1727 (2 strains, 8\%), and one strain each for all other STs. Figure 2 shows ST distribution across the entire sample.

The core-SNP phylogenetic analysis showed that strains belonging to the same ST clustered in the same groups, without regard to CR susceptibility or resistance (see Additional file 3). Moreover, the SNP analysis allows distinguishing each different strain.

\section{Virulome: CR-Kp group versus CS-Kp group}

Virulence factors distribution in CR-Kp and CS-Kp is detailed in Table 3. The mrk operon, which encodes type 3 fimbriae, was detected in all isolates. The $w z i$ gene, involved in the capsule attachment to the host cell surface and used for the prediction of capsular (K) antigen type, was found in all CR-Kp isolates (100\%), in particular, 3 strains carried the $w z i-2$ allele (see Additional file 4). Regarding the iron acquisition systems, the distribution of genes encoding for the yersiniabactin system $(y b t)$, its receptor fyuA and the aerobactin system did not show significant differences between CR-Kp and CS-Kp (Table 3). Klebsiella ferrous iron uptake system ( $k f u A, k f u B$ and $k f u C$ genes), the two-component system $k v g \mathrm{AS}$ and the microcin E495 were significantly $(p<0.05)$ prevalent in the CS-Kp group (28\%) compared to the CR-Kp one (4\%) (Table 3).

Table 4 displays the comparative analysis of virulence determinants between CR-Kp and CS-Kp belonging to the same ST. All strains belonging to ST405, regardless of their resistance profile, had the same determinants (mrk, wzi-143, ybt, microcin E495 and kvgAS. Regarding the strains belonging to ST307, both CR-Kp and CS-Kp strains had the mrk operon, wzi-173 and ybt operon,
Table 4 Distribution of virulence determinants in STs clone of $K$. pneumoniae CR and CS

\begin{tabular}{lll}
\hline STs & CR-Kp & CS-Kp \\
\hline ST395 & $m r k, w z i-2, y b t, y u c$, & $m r k, w z i-2, y b t, y u c$ \\
ST307 & $m r k, w z i-173 y b t^{1}$ & $m r k, w z i-173, y b t$ \\
ST392 & $m r k, w z i-187$ & $m r k, w z i-187$ \\
ST405 & $m r k, w z i-143, y b t$, kvgAS, E495 & $m r k, w z i-143, y b t, k v g A S$, E495 \\
\hline
\end{tabular}

${ }^{1}$ missing in one of the three $\mathrm{CR}$ isolates

with the exception of the $5 \mathrm{R}$ isolate, lacking $y b t$ genes (Table 4).

\section{Virulome subanalysis by STs across the CR-Kp group} CR-Kp isolates belonging to ST512, ST258 did not carry virulence determinants other than mrk and wzi (Table 4). The three strains belonging to ST395 carried four virulence determinants: $m r k$, fyuA/irp2, iucABCD and wzi type 2. wzi gene type 27 was found in the two ST392 isolates together with the mrk operon. Strains belonging to ST348 carried the mrk operon, $y b t$ operon and wzi-94 gene, whereas the ST101 strain exhibited mrk, ybt operon, wzi type 17 and the kfuABC system. The ST405 isolate was the only one that carried the kvgAS operon and the microcin E495, together with the mrk operon, $y b t$ operon and the wzi-143.

\section{Resistome analysis across the CR-Kp group}

The in silico $\beta$-lactamase characterisation of CR-Kp isolates showed that the most frequent carbapenemase-producing gene was blaSHV (100\%). In particular, SHV variant 182 was detected in 16 out of 25 isolates (64\%), while variant 28 in four strains (16\%), three ST307 and the only ST101 isolate. blaKPC was identified in $88 \%$ of isolates and the most common variant was blaKPC-3 (90.9\%). blaTEM was found in 23 isolates (92\%), all of which were variant 1 and blaCTX-M (variant 15) was found in 8 isolates (32\%). blaOXA was found in 22 isolates (88\%), 14 of these were

Table 3 Distribution of virulence factors in carbapenem resistant and susceptible $K$. pneumoniae strains

\begin{tabular}{|c|c|c|c|c|}
\hline Virulence factors & Locus-Genes & $\begin{array}{l}\text { K. pneumoniae CR } \\
\mathrm{n}(\%)\end{array}$ & $\begin{array}{l}\text { K. pneumoniae CS } \\
\mathrm{n}(\%)\end{array}$ & $P$ value \\
\hline Type 3 fimbries & mrk operon & $25(100 \%)$ & $25(100 \%)$ & 1.000 \\
\hline Capsule & $w z i$ & 25 (100\%) & $23(92 \%)$ & 0.552 \\
\hline \multirow{3}{*}{$\begin{array}{l}\text { Iron acquisition } \\
\text { systems }\end{array}$} & ybt operon & $10(40 \%)$ & $15(60 \%)$ & 0.089 \\
\hline & $\begin{array}{l}\text { Aerobactin iron acquisition } \\
\text { siderophore } \\
\text { (iuCABCD) }\end{array}$ & $3(12 \%)$ & $3(12 \%)$ & 1.000 \\
\hline & $\begin{array}{l}\text { Klebsiella } \\
\text { Ferric ionic-uptake system } \\
\text { (kfuABC) }\end{array}$ & $1(4 \%)$ & $7(28 \%)$ & 0.020 \\
\hline $\begin{array}{l}\text { Two-component } \\
\text { system }\end{array}$ & kvgAS & $1(4 \%)$ & 7 (28\%) & 0.020 \\
\hline Bacteriocin & Microcin E492 & $1(4 \%)$ & $7(28 \%)$ & 0.020 \\
\hline
\end{tabular}


Table 5 K. pneumoniae CR profile: colistin susceptibility, carbapenemase, ESBL and beta-lactamases genes

\begin{tabular}{|c|c|c|c|c|c|c|c|}
\hline STs & ID & $\mathrm{CS}(\mathrm{mg} / \mathrm{L})$ & bla KPC & bla SHV & bla CTX-M & bla TEM & bla OXA \\
\hline \multirow[t]{8}{*}{ ST512 } & $6 \mathrm{R}$ & $<=1$ & 3 & 182 & - & 1 & 9 \\
\hline & $7 R$ & $<=1$ & 3 & 182 & - & 1 & 9 \\
\hline & $8 R$ & $<=1$ & 3 & 182 & - & - & - \\
\hline & $11 \mathrm{R}$ & $<=1$ & 3 & 182 & - & 1 & 9 \\
\hline & $16 R$ & $<=1$ & 3 & 182 & - & 1 & 9 \\
\hline & $19 \mathrm{R}$ & $>4$ & 3 & 182 & - & - & 1 \\
\hline & $22 \mathrm{R}$ & $<=1$ & 3 & 182 & - & 1 & 9 \\
\hline & $25 \mathrm{R}$ & $<=1$ & 3 & 182 & - & 1 & 9 \\
\hline \multirow[t]{5}{*}{ ST258 } & $12 \mathrm{R}$ & $<=1$ & 3 & 182 & - & 1 & 9 \\
\hline & $18 R$ & $<=1$ & 3 & 182 & - & 1 & 9 \\
\hline & $21 \mathrm{R}$ & $<=1$ & 3 & 182 & - & 1 & 9 \\
\hline & $23 \mathrm{R}$ & $>4$ & 3 & 182 & - & 1 & 9 \\
\hline & $24 R$ & $<=1$ & 3 & 182 & - & 1 & 9 \\
\hline \multirow[t]{3}{*}{ ST395 } & $2 R$ & $<=1$ & 3 & 182 & - & 1 & - \\
\hline & $4 R$ & $<=1$ & 3 & 182 & 15 & 1 & 1 \\
\hline & $10 R$ & $<=1$ & 3 & 182 & - & 1 & - \\
\hline \multirow[t]{3}{*}{ ST307 } & $5 \mathrm{R}$ & $<=1$ & 9 & 28 & 15 & 1 & 9 \\
\hline & $13 R$ & $<=1$ & 3 & 28 & 15 & 1 & $1 / 9$ \\
\hline & $20 \mathrm{R}$ & $>4 \mathrm{R}$ & 2 & 28 & - & 1 & $1 / 9$ \\
\hline \multirow[t]{2}{*}{ ST392 } & $1 \mathrm{R}$ & $<=1$ & 3 & 67 & 15 & 1 & 9 \\
\hline & $3 R$ & $<=1$ & - & 67 & 15 & 1 & 1 \\
\hline \multirow[t]{2}{*}{ ST 348} & $15 R$ & $>4 \mathrm{R}$ & - & 81 & 15 & 1 & 1 \\
\hline & $17 \mathrm{R}$ & $<=1$ & - & 81 & 15 & 1 & 1 \\
\hline ST 101 & $9 \mathrm{R}$ & $<=1$ & 3 & 28 & - & 1 & 9 \\
\hline ST 405 & $14 R$ & $>4 \mathrm{R}$ & 3 & 76 & 15 & 1 & $1 / 9$ \\
\hline
\end{tabular}

variant 9 (63.6\%), 5 were variant $1(22.72 \%)$ and 3 isolates (13.63\%) presented both variants, blaOXA-1 and blaOXA9. Five isolates, one belonging to ST395, two to ST307, one to ST101 and one to ST405 owned all the five carbapenemase-producing genes investigated (Table 5). Complete data from the in silico analysis (e.g. encoding efflux pumps, heavy metal resistance system, genes involved in aminoglycoside and fluoroquinolone resistance) are shown in Additional file 2.

\section{Discussion}

The epidemiology of CR-Kp in our geographic area (Palermo, Italy) has already been characterized in the late 2008 at the emergence of CR-Kp ST258 clones [20]. However, several reports have suggested an ongoing epidemiological change in the last years. In fact, whereas CC258 (ST258 and ST512) is still prevalent, several other STs are emerging and circulating [23, 24, 28].

This study set out with the aim of assessing the current dissemination and genetic characteristics of $K$. pneumoniae in Palermo. Even though a larger sample may have allowed to gain more representative data, our preliminary data reveal a complex situation characterized by: 1) high genome "plasticity" of both CR-Kp and $\mathrm{CS}-\mathrm{Kp}$, due to the presence of several virulence and resistance determinants carried by mobile genetic elements; 2) a CR-Kp group showing an important genetic diversity of lineages, with 8 different STs identified; 3) an overlapping of multi-drug resistance and hyper virulence traits in the CR-Kp group.

Regarding STs, our comprehensive analysis indicates that, although ST258 and ST512 remain the most representative ones, other STs (e.g. ST307, ST395, ST392, ST348, ST405 and ST101) have been detected in our area. These results are consistent with the surveillance data from other authors [20-24, 28]. Moreover, our findings on $\beta$-lactamase characterisation showed that the blaSHV gene was the most commonly found in our sample, followed by blaTEM and blaKPC, deviating from other studies [11, 29, 30], while respect to the KPC-type enzyme our results are in line with those of other studies - as the most commonly encountered is 
blaKPC-3 [21, 23, 31-33]. Regarding STs, the most represented across the CR-Kp group were ST512 and ST258. These isolates did not carry any distinguishing virulence determinant (except for the mrk operon and $w z i$ gene, which were present in all the samples), suggesting that the success of these clones may only depend on the acquisition of the blaKPC gene [9, 15, 34].

Among the ST512 isolates, we found the 19R strain profile to be particularly interesting. This colistinresistant strain was the only one in its ST group that showed both the yersiniabactin system and its receptor, which has been detected in several $K$. pneumoniae MDR clones; despite of this, the clinical effect of the yersiniabactin system on CR-Kp infections has not been clearly determined $[4,35,36]$.

Our data also match those of reports suggesting the recent spread of the well-known clone ST307. In fact, in 2014, a CR-Kp ST307 clone carrying the blaKPC-3, coproducing the blaCTX-M-15, has been isolated in three Palermo's Hospitals [23]. The virulome analysis of our ST307 strains has revealed, that 5R isolate was the only one missing the yersiniabactin locus in its ST group. Furthermore, $13 \mathrm{R}$ and $5 \mathrm{R}$ isolates, two of the three strains belonging to ST307, showed the copresence of all five carbapenem resistance genes analysed. The co-presence of the detected virulence factors together with the MDR phenotype may explain the diffusion of this clone and the severity of its infections, which have been reported as characterised by higher mortality rates (over 50\%) compared to other clones $[37,38]$. Moreover, leaving aside specific considerations about the clone ST307, the co-presence of five carbapenem resistance genes that we detected in five strains of our sample $(20 \%)$ is in line with that of a study by Ferreira et al., which has recently reported that $72 \%$ of the $K$. pneumoniae isolated from a Brazilian Intensive care Unite co-produced blaKPC, blaOXA, blaTEM, blaSHV, and blaCTX-M [39].

Another emerging clone, already isolated by other authors in Palermo and also detected in our CR-Kp sample, was the ST395 [40]. Strains belonging to this clone presented the wzi2 allele, which encodes the type K2 capsular antigen that represents one of the most virulent serotypes, thus defined "more virulent" [41, 42]. CR-Kp ST395 strains also carried the yersiniabactin system and its receptor and were the only resistant isolates to possess the aerobactin system (iucABCD). Two aspects of these strains should be addressed here: i) $4 \mathrm{R}$ isolate showed the co-presence of five carbapenem resistance genes; ii) to the best of our knowledge, this is the first time that a CR-Kp ST395 clone is reported as carrying a type 2 capsule. This finding was unexpected and seems to be in contrast with the concept that MDR and hyper virulent clonal complexes do not normally overlap [42].
Moreover, our data confirm the spreading of the ST392 clone. A recently published study by Di Mento and colleagues has reported, for the first time, the isolation of a K. pneumoniae strain ST392 blaKPC-3 carrying the blaCTX-M-15, blaSHV-11 and blaTEM-1 genes from a patient in Palermo who had undergone kidneypancreas transplantation [43]. In our CR-Kp ST392 sample, the $1 \mathrm{R}$ strain which was isolated from blood at the General and Emergency Surgery Department in 2015, showed the co-existence of blaKPC-3, blaSHV-67, blaCTX-M-15, blaTEM-1 and blaOXA-9. This result is interesting as the only other KPC-producing $K$. pneumoniae ST392 ever reported was isolated in China but with a different isoform, KPC-2 [44]. However, it is important to underline that the other ST392 strain (3R) in our CRKp sample did not carry the blaKPC gene, suggesting that the ST392 KPC-3 clone may have acquired the resistance gene through horizontal transmission, as described by other authors [43].

This study also revealed two MDR CR-Kps belonging to ST348 and carrying the blaCTX-M-15, blaSHV-81, blaTEM-1 and blaOXA-1 genes. Strains belonged to ST348, but harboured the blaKPC-3, which had been previously reported as responsible of several epidemic events in Portugal [45]. Considering that one of our isolates was colistin-resistant and the ease with which $K$. pneumoniae acquires the blaKPC gene, we can consider the MDR CR-Kp ST348 strains as possibly emerging high-risk clones.

Three other important data that emerge from our results and complete the description of the CR-Kp epidemiological scene in Palermo are: firstly, the circulation of strains belonging to ST101. This clone was previously recognized worldwide as a high risk carbapenemproducing clone [30] and has already been identified in Palermo and in the North of Italy [46-48]. Our ST101 strain (9R) carried the blaKPC-3, blaSHV-28, blaTEM-1 and blaOXA-9 genes and the Klebsiella ferrous uptake system, which is typically found in K. pneumoniae hypervirulent strains $[49,50]$; secondly, the characteristic of the strain belonging to ST405, which carried the blaKPC-3, blaCTX-15, blaSHV-76, blaTEM-1 and blaOXA-1/9 genes, the $a a c 6-I b-c r$ and $q n r B$ and was resistant to colistin. Strains from ST405 have similarly caused an outbreak in a Spanish Hospital neonatal unit [50] and have already been isolated in Palermo [24]. It is important to underline that the genes involved in microcin production and kvgA/ $\mathrm{S}$ system were detected in all isolates belonging to ST405, both resistant and susceptible to carbapenem, possibly indicating a stable and characteristic genetic pattern for these clones; lastly to the best of our knowledge this is the first study to report in Italy the isolation of five CR-Kp isolates belonging to different STs showing the co-presence of five carbapenem resistance genes. 


\section{Conclusions}

These results are significant in at least two major respects. Overall, this study strengthens the idea that the epidemiological frame in the Palermo area (Sicily, Italy) is shifting and new MDR clones are emerging. However, our analysis, which included the comparison of the virulence degree of CS-Kp and CR-Kp isolates, has unexpectedly revealed that the latter are acquiring highlyvirulent determinants and the co-presence of more resistance genes. Undoubtedly, since co-existence of antibiotic resistance and virulence factors may lead to lifethreatening untreatable and invasive $K$. pneumoniae infections, this is an important issue to take into consideration for future genomic surveillance studies.

\section{Supplementary information}

Supplementary information accompanies this paper at https://doi.org/10. 1186/s12879-019-4565-3.

Additional file 1. K. pneumoniae $C R$ antibiotic resistance profile. Results of antibiotic resistance assay of $K$. pneumoniae $C R$.

Additional file 2. K. pneumoniae $C R$ in silico analysis of resistome and virulome. Results of in silico analysis of sequences encoding for efflux pumps, heavy metal resistance system, and genes involved to aminoglycoside and fluoroquinolone resistance.

Additional file 3. wzi analysis of CR-K and CS-K. Table of contig and allele of wzi gene in K. pneumoniae CR and CS.

Additional file 4. SNP phylogenetic tree. Core Single-Nucleotide Polymorphisms dendrogram.

\section{Abbreviations}

CR-Kp: Carbapenem-resistant K. pneumoniae; CS-Kp: Carbapenem-susceptible K. pneumoniae; NGS: Next generation sequencing; MLST: Multi-locus sequence typing; SNP: Core single nucleotide polymorphism; CC: Clonal complex; ST: Sequence type; WHO: World Health Organization; CDC: US Centers for Disease Control and Prevention; MDR: Multi drug resistant

\section{Acknowledgements}

We should like to express our gratitude to SciencED medical communication for its technical support.

\section{Consent to publish}

Not applicable.

\section{Authors' contributions}

Conceived and designed the study: TF, AG, FL. Managed the conduction of the study: TF, AG, FL, MA. Collected samples: CM, MA, TF. Microbiological analysis and molecular typing: $B G, A A, A F, S F, G P$. Analysed the data: BG, AA, $A F, S F, G P, A C$. Drafted the manuscript: AG, TF, MA, FL. Drafted the revisions: AC, TF. All authors read and approved the final manuscript.

\section{Funding}

The authors received no specific funding for this work.

\section{Availability of data and materials}

The dataset used and analyzed during the current study are available from the corresponding author on reasonable request.

\section{Ethics approval and consent to participate}

All examined carbapenem-resistant Klebsiella pneumoniae and carbapenemsensible Klebsiella pneumoniae isolates were isolated during the routine diagnostics and preserved according to local epidemiological surveillance regulations. Written informed consent for routine diagnostic and medical procedures was collected for each patient.
All data used in the study were anonymized, according to the requirements set by Italian Data Protection Code (leg. Decree 196/2003) and by the general authorizations issued by the Data Protection Authority. Approval by the Ethics Committee was obtained by Azienda Ospedaliera Universitaria Policlinico "P. Giaccone" of Palermo (protocols n07/2019).

\section{Competing interests}

The author declare that they have no competing interests.

\section{Author details}

${ }^{1}$ Department of Health Promotion, Mother and Child Care, Internal Medicine and Medical Specialties, University of Palermo, Via del Vespro 133, 90127 Palermo, Italy. ${ }^{2}$ Scientific Department, Army Medical Center, Via S. Stefano Rotondo, 4 - 00184 Rome, Italy.

Received: 1 September 2018 Accepted: 16 October 2019

Published online: 04 November 2019

References

1. World Health Organization. Global priority list of antibiotic-resistant bacteria to guide research, discovery, and development of new antibiotics. 27 February 2017; $1-7$.

2. Centers for Disease Control and Prevention. Antibiotic Resistance Threats in the United States, 2013; http://www.cdc.gov/drugresistance/threat-report-2013

3. Department of Health and Department for Environment Food \& Rural Affairs. UK Five Year Antimicrobial Resistance Strategy 2013 to 2018. 10 September 2013. https://www.gov.uk/government/publications/uk-5-yearantimicrobial-resistance-strategy-2013-to-2018.

4. Holt KE, Wertheim H, Zadoks RN, Baker S, Whitehouse CA, Dance D, Jenney A, Connor TR, Hsu LY, Severin J, Brisse S, Cao H, Wilksch J, Gorrie C, Schultz MB, Edwards DJ, Nguyen KV, Nguyen TV, Dao TT, Mensink M, Minh VL, Nhu NT, Schultsz C, Kuntaman K, Newton PN, Moore CE, Strugnell RA, Thomson NR. Genomic analysis of diversity, population structure, virulence, and antimicrobial resistance in Klebsiella pneumoniae, an urgent threat to public health. Proc Natl Acad Sci U S A. 2015;7(112):E3574-81.

5. Bandeira M, Carvalho AP, Duarte A, Jordao L. Exploring dangerous connections between Klebsiella pneumoniae biofilms and healthcareassociated infections. Pathogens. 2014:3:720-31.

6. Ko WC, Paterson DL, Sagnimeni AJ, Hansen DS, Von Gottberg A, Mohapatra S, Casellas JM, Goossens H, Mulazimoglu L, Trenholme G, Klugman KP. McCormack JG, Yu VL. Community-acquired Klebsiella pneumoniae bacteremia: global differences in clinical patterns. Emerg Infect Dis. 2002:8:160-6.

7. Vogwill T, MacLean RC. The genetic basis of the fitness costs of antimicrobial resistance: a meta-analysis approach. Evol Appl. 2015;8:284-95.

8. Ramirez MS, Traglia GM, Lin DL, Tran T, Tolmasky ME. Plasmid-mediated antibiotic resistance and virulence in gram-negatives: the Klebsiella pneumoniae paradigm. Microbiol Spectr. 2014;2:1-15.

9. Hennequin C, Robin F. Correlation between antimicrobial resistance and virulence in Klebsiella pneumoniae. Eur J Clin Microbiol Infect Dis. 2016:35:333-41.

10. Nordmann P, Poirel L, Walsh TR, Livermore DM. The emerging NDM carbapenemases. Trends Microbiol. 2011:19:588-95.

11. Lee CR, Lee JH, Park KS, Kim YB, Jeong BC, Lee SH. Global dissemination of Carbapenemase-producing Klebsiella pneumoniae: epidemiology, genetic context, treatment options, and detection methods. Front Microbiol. 2016;7:895.

12. Munoz-Price S, Poirel L, Bonomo RA, et al. Clinical epidemiology of the global expansion of Klebsiella pneumoniae carbapenemases. Lancet Infect Dis. 2013;13:785-96.

13. Cantón R, Akóva M, Carmeli Y, Giske CG, Glupczynski Y, Gniadkowski M, Livermore DM, Miriagou V, Naas T, Rossolini GM, Samuelsen $\varnothing$, Seifert $H_{4}$ Woodford N, Nordmann P. Rapid evolution and spread of carbapenemases among Enterobacteriaceae in Europe. Clin Microbiol Infect. 2012;18:413-31.

14. Deleo FR, Chen L, Porcella SF, Martens CA, Kobayashi SD, Porter AR, Chavda KD, Jacobs MR, Mathema B, Olsen RJ, Bonomo RA, Musser JM, Kreiswirth BN. Molecular dissection of the evolution of carbapenem-resistant multilocus sequence type 258 Klebsiella pneumoniae. Proc Natl Acad Sci U S A. 2014; 111:4988-93.

15. Bowers JR, Kitchel B, Driebe EM, et al. Genomic analysis of the emergence and rapid global dissemination of the clonal group 258 Klebsiella pneumoniae pandemic. PLoS One. 2015;10:e0133727. 
16. Pitout JDD, Nordmann P, Poirel L. Carbapenemase-producing Klebsiella pneumoniae, a key pathogen set for global nosocomial dominance. Antimicrob Agents Chemother. 2015;59:5873-84.

17. Giani T, D'Andrea MM, Pecile P, Borgianni L, Nicoletti P, Tonelli F, et al Emergence in Italy of Klebsiella pneumoniae sequence type 258 producing KPC-3 carbapenemase. J Clin Microbiol. 2009:47:3793-4.

18. European Centre for Disease Prevention and Control. Antimicrobial resistance surveillance in Europe 2016. Annual report of the European antimicrobial resistance surveillance network (EARS-net). Stockholm: ECDC; 2017.

19. Gaiarsa S, Comandatore F, Gaibani P, Corbella M, Dalla Valle C, Epis S, Scaltriti E, Carretto E, Farina C, Labonia M, Landini MP, Pongolini S, Sambri V, Bandi C, Marone P, Sassera D. Genomic epidemiology of Klebsiella pneumoniae: the Italian scenario, and novel insights into the origin and global evolution of resistance to carbapenem antibiotics. Antimicrob Agents Chemother. 2015;59:389-96.

20. Mammina C, Palma DM, Bonura C, Plano MRA, Monastero R, Sodano C, Calà C, Tetamo R. Outbreak of infection with Klebsiella pneumoniae sequence type 258 producing Klebsiella pneumoniae carbapenemase 3 in an intensive care unit in Italy. J Clin Microbiol. 2010;48:1506-7.

21. Mezzatesta ML, Gona F, Caio C, Petrolito V, Sciortino D, Sciacca A, Santangelo C, Stefani S. Outbreak of KPC-3-producing, and colistin-resistant, Klebsiella pneumoniae infections in two Sicilian hospitals. Clin Microbiol Infect. 2011;17:1444-7.

22. Simpson JT, Wong K, Jackman SD, Schein JE, Jones SJ, Birol I. ABySS: a parallel assembler for short read sequence data. Genome Res. 2009;19:1117-23.

23. Geraci DM, Bonura C, Giuffrè M, Saporito L, Graziano G, Aleo A, Fasciana T, Di Bernardo F, Stampone T, Palma DM, Mammina C. Is the monoclonal spread of the ST258, KPC-3-producing clone being replaced in southern Italy by the dissemination of multiple clones of carbapenemnonsusceptible, KPC-3-producing Klebsiella pneumoniae? Clin Microbiol Infect. 2015;21:e15-7.

24. Bonura C, Giuffrè M, Aleo A, Fasciana T, Di Bernardo F, Stampone T, Giammanco A. MDR-GN working group, Palma DM, Mammina C. an update of the evolving epidemic of blaKPC carrying Klebsiella pneumoniae in Sicily, Italy, 2014: emergence of multiple non-ST258 clones. PLoS One. 2015;10:e0132936.

25. EUCAST (European Committee on Antimicrobial Susceptibility Testing), 2012; Breakpoint tables for interpretation of MICs and zone diameters. Version 2.0, valid from 2012-01-01. http://www.eucast.org/clinical_breakpoints/

26. Gardner SN, Hall BG. When whole-genome alignments just won't work: kSNP V2 software for alignment-free SNP discovery and phylogenetics of hundreds of microbial genomes. PLoS One. 2013;8:e81760.

27. Huson DH, Scornavacca C. Dendroscope 3: an interactive tool for rooted phylogenetic trees and networks. Syst Biol. 2012;61:1061-7.

28. Maida CM, Bonura C, Geraci DM, Graziano G, Carattoli A, Rizzo A, Torregrossa MV, Vecchio D, Giuffrè M. Outbreak of ST395 KPC-producing Klebsiella pneumoniae in a neonatal intensive care unit in Palermo. Italy Infect Control Hosp Epidemiol. 2018;39(4):496-8.

29. Rimoldi SG, Gentile B, Pagani C, Di Gregorio A, Anselmo A, Palozzi AM, Fortunato A, Pittiglio V, Ridolfo AL, Gismondo MR, Rizzardini G, Lista F. Whole genome sequencing for the molecular characterization of carbapenem-resistant Klebsiella pneumoniae strains isolated at the Italian ASST Fatebenefratelli Sacco Hospital, 2012-2014. BMC Infect Dis. 2017;17:666.

30. Mammina C, Bonura C, Di Bernardo F, Aleo A, Fasciana T, Sodano C, Saporito MA, Verde MS, Tetamo R, Palma DM. Ongoing spread of colistinresistant Klebsiella pneumoniae in different wards of an acute general hospital, Italy, June to December 2011. Euro Surveill. 2012;16;17(33).

31. Santino I, Bono S, Nuccitelli A, Martinelli D, Petrucci C, Alari A. Microbiological and molecular characterization of extreme drug-resistant carbapenemase-producing Klebsiella pneumoniae isolates. Int J Immunopathol Pharmacol. 2013;26:785-90.

32. Di Carlo P, Pantuso G, Cusimano A, D'Arpa F, Giammanco A, Gulotta G, et al. Two cases of monomicrobial intraabdominal abscesses due to KPC-3 Klebsiella pneumoniae ST258 clone. BMC Gastroenterol. 2011;11:103.

33. Calia C, Pazzani C, Oliva M, Scrascia M, Lovreglio P, Capolongo C, Dionisi AM, Chiarelli A, Monno R. Carbapenemases-producing Klebsiella pneumoniae in hospitals of two regions of southern Italy. APMIS. 2017;125: 491-8.

34. Bialek-Davenet S, Criscuolo A, Ailloud F, Passet V, Jones L, Delannoy-Vieillard A-S, Garin B, Le Hello S, Arlet G, Nicolas-Chanoine MH, Decré D, Brisse S.
Genomic definition of hypervirulent and multidrug-resistant Klebsiella pneumoniae clonal groups. Emerg Infect Dis. 2014;20:1812-20.

35. Bachman MA, Oyler JE, Burns SH, Caza M, Lépine F, Dozois CM, Weiser JN. Klebsiella pneumoniae yersiniabactin promotes respiratory tract infection through evasion of lipocalin 2. Infect Immun. 2011;79:3309-16.

36. Lawlor MS, O'Connor C, Miller VL. Yersiniabactin is a virulence factor for Klebsiella pneumoniae during pulmonary infection. Infect Immun. 2007;75: 1463-72.

37. Villa L, Feudi C, Fortini D, lacono M, Bonura C, Endimiani A, Mammina C, Carattoli A. Complete genome sequence of KPC-3- and CTX-M-15producing Klebsiella pneumoniae sequence type 307. Genome Announc. 2016:4:e00213-6.

38. Villa L, Feudi C, Fortini D, Brisse S, Passet V, Bonura C, Endimiani A, Mammina C, Ocampo AM, Natalia Jimenez J, Doumith M, Woodford N, Hopkins K, Carattoli A. Diversity, virulence, and antimicrobial resistance of the KPC-producing Klebsiella pneumoniae ST307 clone. Microb Genom. 2017;3:e000110.

39. Ferreira RL, da Silva BCM, Rezende GS, Nakamura-Silva R, Pitondo-Silva A, Campanini EB, Brito MCA, da Silva EML, Freire CCM, Cunha AF, Pranchevicius MC. High Prevalence of Multidrug-Resistant Klebsiella pneumoniae Harboring Several Virulence and $\beta$-Lactamase Encoding Genes in a Brazilian Intensive Care Unit. Front Microbiol. 2019;9:3198.

40. Cubero M, Marti S, Domínguez MÁ, González-Díaz A, Berbel D, Ardanuy C. Hypervirulent Klebsiella pneumoniae serotype K1 clinical isolates form robust biofilms at the air-liquid interface.PLoS One. 2019;18;14(9):e0222628. https://doi.org/10.1371/journal.pone.0222628

41. Li W, Sun G, Yu Y, Li N, Chen M, Jin R, Jiao Y, Wu H. Increasing occurrence of antimicrobial-resistant hypervirulent (hypermucoviscous) Klebsiella pneumoniae isolates in China. Clin Infect Dis. 2014;58:225-32.

42. Di Mento G, Cuscino N, Carcione C, Cardinale F, Conaldi PG, Douradinha B. Emergence of a Klebsiella pneumoniae ST392 clone harbouring KPC-3 in an Italian transplantation hospital. J Hosp Infect. 2018;98:313-4.

43. Yang J, Ye L, Guo L, Zhao Q, Chen R, Luo Y, Chen R, Tian S, Zhao J, Shen D, Han L. A nosocomial outbreak of KPC-2-producing Klebsiella pneumoniae in a Chinese hospital: dissemination of ST11 and emergence of ST37, ST392 and ST395. Clin Microbiol Infect. 2013;19:E509-15.

44. Rodrigues C, Bavlovic J J, Machado E, Amorim J, Peixe L, Novais Â. KPC-3Producing Klebsiella pneumoniae in Portugal Linked to Previously Circulating Non-CG258 Lineages and Uncommon Genetic Platforms (Tn4401d-IncFIA andTn4401d-IncN). Front Microbiol. 2016;7:1000.

45. Mammina C, Bonura C, Aleo A, Fasciana T, Brunelli T, Pesavento G, Degl'Innocenti R, Nastasi A. Sequence type 101 (ST101) as the predominant carbapenem-non-susceptible Klebsiella pneumoniae clone in an acute general hospital in Italy. Int J Antimicrob Agents. 2012;39:543-5.

46. Mammina C, Aleo A, Bonura C, Calà C, Degl'Innocenti R, Conti A, Pecile P, Pesavento G, Nastasi A. Multiclonal emergence of carbapenem-resistant Klebsiella pneumoniae in Tuscany. Italy Int J Antimicrob Agents. 2010;36:576-8.

47. Del Franco M, Paone L, Novati R, Giacomazzi CG, Bagattini M, Galotto C, Montanera PG, Triassi M, Zarrilli R. Molecular epidemiology of carbapenem resistant Enterobacteriaceae in Valle d'Aosta region, Italy, shows the emergence of KPC-2 producing Klebsiella pneumoniae clonal complex 101 (ST101 and ST1789). BMC Microbiol. 2015;15:260.

48. Russo TA, Olson R, MacDonald U, Metzger D, Maltese LM, Drake EJ, Gulick AM. Aerobactin mediates virulence and accounts for increased siderophore production under ironlimiting conditions by hypervirulent (hypermucoviscous) Klebsiella pneumoniae. Infect Immun. 2014;82:2356-67.

49. Ma LC, Fang CT, Lee CZ, Shun CT, Wang JT. Genomic heterogeneity in Klebsiella pneumoniae strains is associated with primary pyogenic liver abscess and metastatic infection. J Infect Dis. 2005;1:117-28.

50. Machuca J, López-Cerero L, Fernández-Cuenca F, Gracia-Ahufinger I, Ruiz-Carrascoso G, Rodríguez-López F, Pascual Á. Characterization of an outbreak due to CTX-M-15-producing Klebsiella pneumoniae lacking the blaOXA-48 gene belonging to clone ST405 in a neonatal unit in southern Spain. J Antimicrob Chemother. 2016;71:2353-5.

\section{Publisher's Note}

Springer Nature remains neutral with regard to jurisdictional claims in published maps and institutional affiliations. 